\title{
Anabases
}

ANABASES Traditions et réceptions de l'Antiquité

$17 \mid 2013$

Varia

\section{Romain VIGNEST, Victor Hugo et les poètes latins. Poésie et réécriture pendant l'exil}

Jean Zaganiaris

\section{OpenEdition}

Journals

Édition électronique

URL : http://journals.openedition.org/anabases/4295

DOI : $10.4000 /$ anabases.4295

ISSN : 2256-9421

Éditeur

E.R.A.S.M.E.

Édition imprimée

Date de publication : 1 mars 2013

Pagination : 307-308

ISSN : 1774-4296

Référence électronique

Jean Zaganiaris, «Romain vignest, Victor Hugo et les poètes latins. Poésie et réécriture pendant l'exil », Anabases [En ligne], 17 | 2013, mis en ligne le 01 avril 2013, consulté le 22 septembre 2020. URL: http://journals.openedition.org/anabases/4295 ; DOI : https://doi.org/10.4000/anabases.4295

Ce document a été généré automatiquement le 22 septembre 2020.

(c) Anabases 


\title{
Romain VIGNEST, Victor Hugo et les poètes latins. Poésie et réécriture pendant l'exil
}

\author{
Jean Zaganiaris
}

\section{RÉFÉRENCE}

Romain VIGNEST, Victor Hugo et les poètes latins. Poésie et réécriture pendant l'exil, Paris, Classiques Garnier, 2011, 433 p.

59 euros / ISBN 978-2-8124-0285-2.

1 Comment penser la place des poètes latins au sein de l'œuvre de Victor Hugo? Comment rendre compte de la dette de l'auteur des Misérables à l'égard de Virgile, Lucrèce, Horace et Juvénal ? C'est l'objet du livre de Romain Vignest, qui a choisi le parti pris judicieux de laisser de côté les thèses sur la "présence inconsciente » des Anciens au sein de l'œuvre de Victor Hugo ou bien les raisonnements considérant que les citations latines sont simplement ornementales. L'intertextualité chez Hugo est liée à un travail de transposition des univers du monde antique au sein de sa poésie : « Dans les Châtiments, le poème "Éblouissements" met en œuvre une transposition du motif du consilium principis, emprunté à la quatrième Satire de Juvénal ; du même coup, ce poème consiste aussi en une imitation du style du satiriste romain.» Bien entendu, cette imitation est non pas reproductive mais créatrice d'une parole propre à Victor Hugo. La tradition latine est utilisée mais aussi revendiquée. L'étude de la formation de Victor Hugo montre que le rapport aux textes latins est le fruit d'une volonté personnelle, s'inscrivant parfois contre le cadre scolaire et pratiquée lors d'exercices nocturnes. Le latin devient très vite sa seconde langue et l'amène à un dialogue avec les Anciens qui durera toute son existence.

2 Par le biais de ces auteurs latins, Victor Hugo va s'initier à un ensemble de thèmes. Tout d'abord, à travers Virgile et Lucrèce, il découvre l'importance de la nature au sein de la 
poésie. La description de l'Arcadie dans les Bucoliques représente la beauté des paysages et des régions illuminés par les vers des poètes. Avec beaucoup de finesse, Romain Vignest montre de quelle façon Victor Hugo utilise et transpose dans son œuvre les descriptions des Latins. La nature incarne également la vertu, la liberté, la vie saine. Chez Virgile, comme chez Hugo, le paysan est libre car il n'est pas corrompu par la violence et la cupidité de la civilisation urbaine, souillée également par les affrontements politiques. Il y a « un authentique bonheur » éprouvé par le poète dans l'intimité de la nature : «La poésie et la nature sont d'essence comparable, puisqu'elles agissent l'une sur l'autre et possèdent les mêmes propriétés. » Ensuite, grâce à Horace, il prend conscience de l'importance du rôle du poète et de l'indépendance d'esprit au sein du travail de création. L'artiste est distant à la fois du peuple et du tyran. Horace amène même Victor Hugo à intégrer dans son œuvre des références à la sexualité et au désir : «Orgie universelle, où tout est mû par le désir sexuel et où partout se croisent les satyres dansants, les nymphes chasseresses. "Victor Hugo évoque la sexualité païenne pour attirer l'attention sur « les représentations grimaçantes du vice » et sur le caractère effrayant d'un monde où "l'instinct sexuel tient lieu d'âme ». Enfin, Juvénal représente aux yeux de Victor Hugo la supériorité de l'esprit, et donc de la poésie, sur la matière. Il lui permet d'affiner la dimension spirituelle de son œuvre, y compris dans un dialogue parfois tourmenté avec le carpe diem d'Horace. Le poème de Hugo " À Juvénal " montre les dangers d'un monde où l'inversion des valeurs de bien et de mal ne peut que mener vers la corruption matérialiste. Dans un des poèmes de la Légende des siècles, il fait référence à la corruption des mœurs évoquée par le poète latin : « Rome buvait, gaie, ivre et la face rougie. Et l'odeur du tombeau sortait de cette orgie.»Cette corruption menace également la société dans laquelle évolue Victor Hugo. Le poète a un rôle moral au sein de la cité et doit - pour reprendre une expression de Walter Benjamin - tirer des « sonnettes d'alarme » lorsqu'il voit poindre la menace d'un péril. Même si l'on peut prendre certaines distances avec la dimension morale de l'œuvre de Victor Hugo et évoquer les combats que l'art a eu à mener contre le puritanisme religieux ou étatique, il n'en demeure pas moins que la dimension politique du champ artistique reste d'une grande actualité ; tout comme ces questions importantes soulevées par Romain Vignest autour de ces héritages antiques, transmis sans aucun testament.

\section{AUTEURS}

\section{JEAN ZAGANIARIS}

CERAM/EGE Rabat

zaganiaris@yahoo.fr 